\title{
sciendo
}

DOI 10.2478/sbe-2019-0002

SBE no. 14(1) 2019

\section{CRITICAL ANALYSIS ON THE AMENDMENTS DISCUSSED, CONCERNING CHANGES IN ACCOUNTING ESTIMATES}

\author{
BURCĂ Valentin \\ "Aurel Vlaicu" University of Arad, Romania \\ NICOLĂESCU Cristina \\ "Aurel Vlaicu" University of Arad, Romania \\ DRĂGUȚ Daniel \\ West University of Timișoara, Romania
}

\begin{abstract}
:
In this article, our main aim is to bring in discussion some of the most controversial points debated along the time on the use of the accounting estimates in financial reporting. More important, we have referred to the Exposure Draft recently closed for comment letters, which addressed some points that will follow to be transformed into several amendments to IAS 8. Our discussion is focused, especially on how professionals can make a clear distinction between changes in accounting estimates and changes in accounting policies. We try to underline the trinomial perspective of this subject, as the changes in accounting estimates impact, not only the financial statements, but can generate issues on auditing those estimates, or on using financial information output on the entity valuation models. Additionally, we try to emphasize the essential role of this distinction between changes in accounting estimates and changes in accounting policies.
\end{abstract}

Key words: IAS 8, estimation, IASB, mark-to-market, conceptual framework

\section{Introduction}

Either we talk about financial statements, or various other forms of corporate reports, all of them are aimed to provide a true and fair view of the position and financial performance a reporting entity encounter along one financial exercise. Nowadays accountants' rationale is the base on preparing financial statements. After only a simple search within the IASs and IFRSs, we can find more than 150 instances referring to accounting estimates, as the reasonable uncertainty accepted on preparing the financial statements allow preparers to use estimates. 
As stated by IAS 8, paragraph 32, accounting estimates can be done in numerous areas, such as: accounts receivables, inventory depreciation, assets or debts fair value determination, the economic lifecycle of equipment or provisions measurement. Either we talk about mark-to-market traditional practices, or mark-to-model specific models (much more impacted by financial estimation models!), the accounting estimates are used in order the financial statements to provide a true and fair view of financial position and performance of the reporting entity.

The question is around measuring the materiality of those accounting estimates in the equation of the decision-making process, especially in the light of IFRIC position, that were signaled by professionals that they are often situations when a change in accounting estimate can be defined as an accounting policy change, or vice-versa. Moreover, we ask ourselves if the accounting estimation models comply with the actual valuation principles issued at an international level. Or, can those accounting estimates be reasonably audited, starting from the international framework of assurances services and auditing missions?

The actual Exposure draft, ED/2017/5, aimed to bring amendments to IAS 8, does not reply to all those questions, but at least want to make some clarifications around the delimitation between the concepts of accounting policy and accounting estimates. It tries to reveal how accounting policies and estimates relate to each other. It wants, as well, to add some guidance about whether changes in valuation techniques and in estimation techniques are changes in accounting estimates. They were expected to be received comments by 15 January 2018.

In this study we will see the main conclusions the public discussion has revealed concerning the opportunity of amending IAS 8. Also, some additional observations are raised to IASB that will have to reflect if they are to be included as additional amendments to IAS 8, or are omitted because of insignificant role on improving the quality of accounting estimates.

\section{State of art concerning IAS 8 revision projects}

Along the last two decades, starting with the transformation of IASC into IASB, the standard IAS 8 Accounting policies, changes in accounting estimates and errors, has become the subject of various discussions and revisions.

The main issue around which they were generated long debates in the area of IAS 8 improvements was especially the relative nature of the standard in some of its essential provisions, like the relative nature of the criteria that allowed non-mandatory accounting changes, or the difficulty of making a clear delimitation between accounting policy changes and changes in accounting estimates.

It has been set up a hierarchical flow in terms of using the guidance concerning how the managers will have to establish accounting policies. Thus, according to IAS 8 , paragraph 12, in case of an event or transaction that is not covered by any of the existing IFRSs of by the Conceptual Framework for Financial Reporting, preparers can refer also to other standard-setters' issued standards, or even to accepted industry practices or accounting policies confirmed along the accounting literature. On those circumstances, the question is what will stop, for instance, the preparers to move slowly their accounting 
policies towards US GAAP, which is known as a principle-based financial reporting framework, but still highly detailed? Moreover, on those circumstances, are the users familiar with US GAAPs?

It has been brought additional guidance concerning the materiality concept, especially in terms of requirements of disclosing information based on its materiality, on financial statements; more exactly, in terms of material omissions and misstatements, IAS $8 \mathrm{go}$ in line with IAS 1 requirements (paragraph 29) and the Conceptual Framework for Financial Reporting (paragraph QC11), that state the characteristic of relevance of the financial information disclosed by financial statements is fundamental and decide the level of financial statements aggregation and the offsetting operations. But, the way IASB has chosen to do this, at least on a partial manner, raise discussions, especially when we refer to IAS 8 that stipulate the accounting policies in IFRSs need not to be applied when the effect of applying them is immaterial (IAS 8, par. IN7 (a)), as even the concept of materiality itself is relatively subjective.

Another important concept introduced in financial reporting framework, within IAS 8 revision, is the concept of impracticability, which is defined as a criteria for exemption from changing comparative information when changes in accounting policies are applied retrospectively and prior period errors are corrected. Even there is given some guidance on applying this criteria of impracticability, around its application there still remain space of debate, as it is relative, with a high degree of subjectivity, exactly like the concept of the materiality. But this can lead to significant effects on financial position and performance of the entity, especially when we talk about complex accounting estimates like the ones used on determining the fair value of different assets or debts which the reporting entity is disclosing on the financial statements, because according to IAS 8, the preparers have the option (well justified!) to restate the opening balances of the financial statements elements starting only with the current period (IAS 8, paragraph $24 \& 44$ ). On those circumstances, we would question how reliable are the financial information, that makes later the preparers to restate the financial statement on a comparative way. Indeed, there is long discussion about the equilibrium between financial information characteristics (Gebhardt et. al., 2014). That is why we underline the fact that international accounting differences will persist (especially on the area of measurement issues!) even in case of completely successful global financial reporting framework harmonization, because of factors like culture, accounting profession, judicial system, capital markets, education, or economic development (Fields et. al., 2001; Kothari et. al., 2010; Nobes \& Stadler, 2015). For instance, the relativeness of IFRSs is visible in case of tangible assets obtained from own production, as the managers can either classify those assets according to IFRS 5, as an assets held for sale, or can just affect them into the operational activity of the entity, case when the assets will have to be classified as tangible assets, according to IAS 16. Even if there is a high probability of selling the asset (IFRS 5, par. 7), with a plan of sale (IFRS 5 , par. 8), IFRS 5 state on paragraph 9, that managers can expand the period needed to sell the assets with one year. We underline this situation, as managers can speculate the trend of one asset on the market, because an asset, according to IFRS 5, par. 15 has to be evaluated at the minimum between the accounting value and the selling value minus the selling costs, while according to IAS 16, this kind of asset has to be recognised at its 
production cost. This way, managers can increase artificially the level of total assets, with obvious impact on financial ratio, like the covenants used by financial institutions to approved financing for an entity.

IASB has eliminated the distinction between fundamental errors and other significant errors, as anyway, they were treated, accounted and reported the same manner in the financial statements.

We can see another significant change around paragraph 36 of the actual standard, which is completed by paragraph 37 . This change stipulate that, in case a change in accounting estimate is confirmed, with direct effect on an asset, a liability, or an item of equity, than the financial statement element has to be adjusted with the carrying amount in the period of change. For instance, in case the regulation in the area of using industrial equipment changes, asking for wider requirements that lead to a significant increase in the initial estimate of the costs of dismantling and removing the asset and restoring the site, according to IAS 37, the provision has to increase accordingly. According to the revision of IAS 8, same treatment should be also for the accounting value of the asset.

More recent changes referring to IAS 8 were decided within the project Disclosure initiative- Principles of disclosure, which has brought in discussion more guidance on applying the concept of materiality, enacted on IFRS Practice Statement: Making Materiality Judgements document.

In September 2014, IASB was acknowledged about various situations on which prepares claimed they were unable to make a clear distinction between a change in accounting policy and a change in accounting estimates, when applying IAS 8. This distinction is extremely important as IAS 8 stipulate that the effects of changes in accounting policies are to be determined retrospectively, while effects generated by changes in accounting estimates have to be integrated on the financial statements elements, but only prospectively. On a first tentative to solve this controversial issue, the Board has decided in May 2015 to amend IAS 8 by stating that:

$>$ changes in measurement basis, or changes in methods used to determine cost measures, specified in specific IFRSs, representing noting but changes in accounting policies;

changes in inputs, assumptions a methods used on the mart-to-model accounting, are to be considered as changes in accounting estimates.

After a deeper analysis of IASB staff, the Board has accepted a set of amendments to IAS 8, but not as part of Annual Improvement process, but within a separate project that makes part of the Disclosure Initiative project. Those amendments referred to:

$>$ the definition of accounting policies and of accounting estimates, in order the concepts become more concise and distinctive;

$>$ clarifications of how accounting policies and accounting estimates relate to each other;

$>$ more guidance that should help the preparers to asses if changes in evaluation techniques and estimation techniques represent or not changes in accounting estimates;

$>$ update examples of estimates provided in IAS 8. 
Together with those amendments, it has been considered also that is necessary a review of the IFRSs directly impacted, in order to avoid any conflicting situation between IAS 8 and other IFRs. Also, it has been agreed that is useful for preparers and users of the financial statements to get some additional guidance about transitional requirements. But, there has been concluded that there is no need for any change in disclosures requirements for accounting estimates, neither within IAS 8, nor referring to any other IFRS.

In the end, IASB has published an Exposure Draft on IAS 8 amendments, on September 2017, namely ED/2017/5. Moreover, in order to harmonize the Conceptual Framework with IAS 8, IAS 1, the IFRS Practice Statement and other linked standards, IASB has issued on September 2017 the ED/2017/6 document. In case of both documents issued by IASB, the deadline for comments to be issued was 15 January 2018.

\section{Results and discussions}

This paper is focused especially on discussing the changes brought with the revision of IAS 8, proposed by IASB recently, on the area of changes in accounting estimates and the delimitation from the changes in accounting policies. This topic is extremely important, especially in the light of the new issued standards, like IFRS 13 Fair Value Measurement, IFRS 15 Revenue from Contracts with Costumers, IFRS 16 Leases, or IFRS 17 Insurance Contracts, to which can be added the IFRSs concerning financial instruments treatments, like IFRS 7 Financial Instruments: Disclosures, or IFRS 9 Financial Instruments.

Accounting estimates have gained a central role on financial statements preparation, either because of economic environment uncertainty, or unfortunately, because of some managers' intentions to manipulate financial data disclosed by financial statements.

They are recent studies revealing that there is need of a high level of financial transparency of the reporting entities that should disclose relevant, reliable and verifiable information, in order the accounting estimates to be reasonably audited (Menzefricke \& Smieliauskas, 2016).

Albrecht et. al. (2017), have revealed the fundamental need of disclosures that provide information about changes in accounting estimates, as managers tend to make abuse of different earnings management techniques in order to declare better financial results.

Nontheless, we emphasize Lev et. al. (2010) study conclusion that state clearly the accounting estimates are limited in value relevance, because they are more correlated with the earnings forecast than with the cash flows, sign that can denote the use of accounting estimates in order to meet managers' financial targets.

Overall, all those studies reach to the same conclusion, drawn up on Hail (2013) study, that figures disclosed by financial statements lose on their value relevance. Moreover, Leuz \& Wysocki (2016) underline the economics of the financial statements, implying the opportunity considerations used on preparing financial statements, based on their own objectives. 
Those studies underline the importance of a higher financial transparency managers have to run, especially on the area of improving financial disclosures, aimed to provide the users of financial statements a clearer image of accountants' rationale used on accounting and reporting processes.

Once with ED/2017/5, the Board has addressed five questions to the ones interested to send comment letters, concerning the changes planned to be made to IAS 8 .

The main problem discussed is IASB to find out a solution of making a clear distinction between accounting policies and accounting estimates, as IFRIC has brought in discussion on 2014 that they were many cases when this distinction was extremely difficult to be done by the preparers. Thus, they were underlined several treatments that have put the preparers in difficulty to distinguish a change in accounting policy from a change in accounting estimates, like: inventory valuation, impairment of goodwill, impairment of loans, depreciation techniques, or amortization techniques. Indeed, this distinction ${ }^{1}$ is fundamental as the changes in accounting estimates are applied prospectively, while the changes in accounting policy are applied retrospectively.

The first question refer to the manner the concept of accounting policy has to be defined.

The second question put in discussion the way it can be reflected in IAS 8 how accounting policies and accounting estimates relate to each other, with the aim to underline the fact the accounting estimates are an instruments for preparers, in order to implement the accounting policies decided. This way, IASB has proposed a definition for the concept of accounting estimates, deleting completely the formulation change in accounting estimate.

The third question ask for opinions if it is opportune to consider selecting an estimation technique or valuation technique as an accounting estimate, but only in case an item in the financial statements cannot be measured with precision.

The forth question is addressing the problem of how to classify the decision of selecting a cost formula for the interchangeable inventories.

The last question is just an open question that allow the respondents to raise any other issues relevant to the discussion around the amendments proposed for IAS 8.

IASB has published in March 2018 a Feedback Summary on the 82 comments letters submitted on this project. The general feedback was positive from most of the participant to the discussion, on the proposals IAB has shown. But, there still remained topics not yet clear, as most of the respondents have claimed the need for additional examples to be embedded on the standard, in order the preparers to have more guidance

\footnotetext{
${ }^{1}$ on the start of the project, they were put in discussion not only those options, but more, namely: (i) the full retrospective application; (ii) the limited retrospective application that would mean the application of the accounting change in policy or estimate start from the beginning of the earliest comparative period presented, situation prescribed on actual IAS 8 in case of impracticability of retrospective application of the changes in the accounting policy; (iii) catch-up adjustment, that would suppose comparatives are not restated and a catch-up adjustment is recognised in the opening balance of the retained earnings, like was one of the alternative treatments applicable before 2005 in case of the voluntary accounting policy changes; (iv) prospective application with enhanced disclosures, that would as an entity to account the changes prospectively, but disclosing information for the current period financial statement line item that is affected, using both the old accounting policy and the new one; $(v)$ prospective application that ask for no financial statements restatement and no disclosure of comparative financial figures, but just the change in accounting policy / estimate to be recognised in the profit \& loss statement;
} 
on how to make distinction between accounting estimates and accounting policies. Moreover, seems that the issue of wording the changes in the standard, or just the terminology problem still persists among the ones involved in the discussion.

The main proposals of IASB to amend IAS 8, are the following:

$>$ in terms of terminology:

$\checkmark$ in the definition of the concept of accounting policy, they have been deleted the words conventions and rules, with no aim to narrow the scope of the standard, but to keep the standard at a higher conceptual level;

$\checkmark$ the term base was replaced by measurement base, which was perceived the reason of a narrowing in scope of IAS 8; some respondents claimed this term still remained undefined;

$\checkmark$ additional to the term measurement base, some respondents raised the need the term practices to be defined within IAS 8, as it is not clear if the preparers can understand by practices only the situation uncovered by IFRSs, but that can be accounted according to paragraphs $10-12$ of IAS 8, namely regulation of other standard-setting bodies;

$\checkmark$ it has been taken off the definition of the change in accounting estimates and replaced with a definition for the concept of accounting estimates, as in IAS 8 there was no definition of change in accounting policy; this way, there is a clearer relation between the concepts of accounting estimates and accounting policy;

$\checkmark$ there has been revised paragraph 32, by replacing the financial assets term with assets and the term financial liabilities with liabilities;

$>$ there has been achieved a large approval concerning the fact that selecting an estimation technique or valuation technique should be classified as making an accounting estimate;

$>$ concerning the question if selecting a cost formula for interchangeable inventory valuation is an accounting policy, or accounting estimate, it has been shown a confirmation of IASB position.

But, on the last question has addressed some challenges to IASB, like:

$>$ the need of additional guidance on applying IAS 8, through more examples;

$>$ the distinction between accounting estimates and accounting errors;

$>$ deletion of Example 3 from the Guidance on Implementing IAS 8;

$>$ applying changes prospectively and retrospectively;

$>$ effective date of amendments.

In the ED/2017/6, referring to materiality concept definition, first question has a clear focus, namely the definition of the concept of materiality and the harmonization with IAS 1 requirements. Thus, IASB enlarge the scope of the definition, by excluding the terms of omission and misstatement, focusing just on the essence of the concept itself, namely that material information is expected to reasonably influence the financial decision of the users of the financial statements. But the term reasonably itself depict a high degree of subjectivism, which might prolong the debate around this concept. Same definition is transferred to IAS 8, emphasizing as in IAS 1, that materiality does not depend on the size, but on the nature or the magnitude of information, or even both. 
From our point of view, now there is a clear distinction between accounting policy and accounting estimate. Even from the definition of the accounting estimate proposed on the Exposure Draft, this should be clear as it states that accounting estimates are judgements or assumptions used in applying an accounting policy when, because of estimation uncertainty, an item in financial statements cannot be measured with precision (ED/2017/5, par. 5). Moreover, from this definition is clearly depicted the relation between an accounting estimate and accounting policy, as the accounting estimates are just instruments to apply accounting policies.

In terms of terminology, we would address just one point, namely the fact that they are wonderings about the definition of concept of measurement base, as from our point of view, this concept is already well described on the Conceptual Framework, par. 4.54-56. More than that, on the recent Conceptual Framework issued on March 2018, there is dedicated a special section addressing the problem of Measurement Bases (Chapter 6). This observation, together with the one concerning how to address the problem of cost formula considered on IAS 2 for interchangeable inventory, we would go in line with Dennis (2014), according to whom rules of structuring an accounting standard would imply the issue of IAS 2 cost formula choice should be addressed within IAS 2, but not within the more conceptual IAS 8 standard.

Same redundancy of requirements, with potential situations when the standards come in conflict is reflected on the side of the stipulations from IAS 1, IAS 8, the Conceptual Framework, IFRS Practice Statement: Making Materiality Judgements and other standards that refer to materiality distinctively. On this direction was issued ED/2017/6 document, launched on September 2018 for debate and discussions, under project Disclosure Initiative- Definition of Material (Amendments to IAS 1 and IAS 8). But this document brings only small amendments to IAS 1, IAS 8 and the Conceptual Framework, oriented especially on clarifying additional wording issues. What can be considered as a central line on this project is the fact that IAS 1 is supposed to provide, manly, a framework concerning the application of the materiality concept, while the rest of the standards just refer to IAS 1. The Conceptual Framework and the IFRS Practice Statement on materiality will just have to be considered complementary to IAS 1.

It is clear the trend where IASB standards go to, namely the standards have to be more specialized in one direction of discussion, with a great high level of conceptual degree, interrelated but not redundant. For instance, a good example is IFRS 13 that concerns issues about fair value on a highly conceptual manner, while the other standards refer, in case of fair value aspects, directly to IFRS 13. Moreover, they are visible the efforts towards avoiding exceptions included on the standards, but they are situations that require this kind of compromise as well. What we would raise as a more visible issue is the increasing vagueness in case of some revisions, like the one of IAS 8, with the situation already mentioned previously in the article, about paragraphs 10-12. This way, preparers can make abuse on referring to other accounting standards, like US GAAP which is much more detailed than IFRSs. More than that, as Jianu (2012) has underlined, the power of intention in financial reporting is justified when making a deep dive into the effects on financial position and financial performance. An example he has reminded is the situation of the financial instruments that according to IAS 39, some of them can be evaluated at fair 
value, namely the financial assets at fair value through profit or loss and available-for-sale financial assets. While the variations in case of the first category of financial instruments is reflected only on the profit \& loss statements, the variations on the second category of financial instruments mentioned, are reflected on the equity item of the financial position, which lead consequently to financial ratios changes only because of preparers intention to sell or not those financial instruments.

Another welcomed revision on IAS 8 refers to extending the scope of IAS 8 , in terms of fair value determination, not only to the financial assets and financial liabilities, but also to other items in the financial statements, according to the revised paragraph 32 of the standard. More than that, if we look closer on Table 1 and Table 2, we can easily figure out that the accounting estimates examples given refer to fair value measurement for various assets or liabilities in the financial statements. Even if the Conceptual Framework admit the historical cost is the most used measurement basis (par. 4.56), in the revised form of the Conceptual Framework the fair value measurement basis become more important.

On this direction, we can underline another general direction stipulated by this Exposure Draft, namely the fact that changes in accounting estimates can generally be generated only by changes in the assumptions based on which the initial accounting estimate was done. This is underlined in IAS 8, par. 34 that state that an entity may need to change an accounting estimate may need revision if changes occur in the circumstances on which the accounting estimate was based or as a result of new information or more experience. Consequently, changes in recognition/de-recognition, classification, disclosure and presentation of items in financial statements are to be considered as accounting policies. This situation is different than the start of the project, as IASB has considered, as a preliminary first proposal that measurement changes will have to be prospectively applied, as a change in accounting estimates.

Moreover, according to paragraph 35 , a change in the measurement basis applied is a change in an accounting policy. Thus, the estimation techniques and valuation techniques, prescribed by the IFRSs will have to be considered as accounting policies, this including even the dilemma if an alternative accounting treatment exist, the choice to switch between the base treatment and the alternative one is reduced to a change in accounting policy. What we still do not have clear in mind is which would be the difference between estimation techniques and valuation techniques, as there is no definition set up within IAS 8, or the revised form of the standard? There is, indeed, reference to the concept of valuation techniques as described on IFRS 13, par. 61-66, but there is no definition, only description of different mark-to-market accounting techniques, or mark-tomodel accounting techniques. The concept is also addressed on the recently revised Conceptual Framework, but the same without any clear definition. Our wondering is if valuation techniques or estimation techniques refer to the same practice of value measurement of the items in the financial statements, or they refer to different topics. For instance, by estimation technique we can mean the way preparers determine the level of provisions for uncertain clients, as preparers have to calculate a probability of income to be realisable. On the other side, when talking about valuation techniques, we think directly to the models proposed by IFRS when evaluating the items in the financial statements. Additionally, the same paragraph state that by its nature, a revision of change in an 
accounting estimate does not relate to prior periods and is not the correction of an error, which statement, we would agree partially, that it makes distinction between accounting estimates and accounting errors. This is quite clear when discussing about change of method $^{1}$ in accounting treatment of an item in the financial statements, as it might be probable that the preparer has chosen the bad accounting policy, based on prior assumptions. But what happens if we ask ourselves if the assumptions that were considered on estimating an item in the financial statements was actually misleading? A clear answer on this question would be extremely useful for any preparer or user of the financial statements, as we have to remind that financial statements restatement, because of some accounting errors detected from the prior period, has to be applied retroactively, not prospectively like in case of the changes in accounting estimates. But, as some respondents on the due process have mentioned, making a clear distinction between accounting errors and accounting estimates is difficult sometimes. In the end, and accounting error is a change in accounting estimate that have to be applied retroactively.

Relevant, but not essential, is the cut off of Example 3, from the guidance section of IAS 8, in order to be eliminated any race of confusion between changes in accounting estimates and changes in accounting policy, as this example was illustrating prospective application of a change in accounting policy when retrospective application was not practicable. This derogation keep confusion among the preparers, as according to par. 25, such a change in accounting policy can be applied exactly like a change in accounting estimates in case the preparer claim that can apply the policy only starting with the current year.

Let us consider one simple example that can show the impact of a change in accounting estimates versus a change in accounting policy, on some essential financial ratios. But, according to IAS 8 amended, par. 32A, it is stated that when an item cannot be measured with precision, selecting an estimation technique or valuation technique to measure that item involves the use of judgement or assumptions in applying the accounting policy for that item. For this reason, selecting that estimation technique or valuation technique constitutes making an accounting estimate. What would happen in case the preparers want to go towards fair value model on valuing financial position items, but there is no active market (as defined by IFRS 13)? Consequently, they should proceed to make use of some internal estimation models, like the ones based on discounted cashflows. So, making the transition on this case from the historical cost base to the fair value base on reporting the balance-sheet, from our point of view, cannot be defined exactly as a change in accounting policy, but just a change in accounting estimates, as they are assumptions and judgement considered. This is why, we would recommend IASB to propose a definition for the uncertainty term as well, as this concept is redundant along the IASs/IFRSs and the Conceptual Framework. It is clear that a threshold is not the best solution considering the complexity of the events and operations reporting entities register, but maybe this concept should be much more connected with the objectives of the financial

\footnotetext{
${ }^{1}$ the decision to consider the change of methods within an accounting treatment was taken against the majority of the respondents that were subjects to several initial surveys conducted on this project, as more than $66 \%$ agreed with this direction; but the decision concerning the best way to represent a change in the inputs and assumptions used to make an estimate was in line with respondents' opinion that confirmed this direction with more than $82 \%$ (AP6 document);
} 
statements and should be much more detailed by each company, within the notes to the financial statements. We think this as this concept has a significant impact on financial figures, as for instance the discount rates (market debt rate, industry return rate, cost of capital etc.) of the cash-flows can be used from a larger range of values, each depending on preparers' perception on the objective of the financial statements.

Company Alfa has purchased in 2010 a production equipment, for the price of 100.000 u.m., having an estimated economic lifetime of 10 years. The equipment is amortized, based on general company accounting policies, using the linear method. At the end of 2012, based on new information revealed on the market technology, the company agree to change equipment's economic lifetime from 10 years to 6 years. On $1^{\text {st }}$ of January 2014, the company decide to change the historical cost convention with the fair value measurement model for all the production equipment. At the end of 2014 , some experts have evaluated the equipment at a fair value of 60.500 u.m. We also have information about the Comprehensive Income Statement and the fact that the balance for the reported result at the end of 2013 was 21000 u.m., while at the end of the 2014 it was reported 32.000 u.m. Tax rate considered is $16 \%$. They are omitted any temporary tax differences, calculated based on IAS 12. The expenses with depreciation for the equipment, as it is affected on the current production, are considered part of the cost of the good sold. The experts appreciated that the fair value of the equipment would have been accounted for the value of 95.000 u.m., as further information they didn't have available. The information was available from beginning of 2012, but the company decided the historical cost is the most suitable valuation base at that moment and they've decided to change only the lifetime cycle of the equipment.

Table 1

\begin{tabular}{|l|r|r|}
\hline The Comprehensive Income Statement & \multicolumn{1}{l|}{$\mathbf{2 0 1 4}$} & \multicolumn{1}{l|}{$\mathbf{2 0 1 3}$} \\
\hline Revenue from sale & 120,000 & 143,500 \\
\hline Cost of goods sold & $(70,000)$ & $(64,500)$ \\
\hline Gross margin & 50,000 & 79,000 \\
\hline Distribution expenses & $(6,500)$ & $(7,950)$ \\
\hline Administrative expenses & $(5,400)$ & $(12,540)$ \\
\hline Operating result & 38,100 & 58,510 \\
\hline Financial revenues & 3,500 & 4,200 \\
\hline Financial expenses & $(1,800)$ & $(1,150)$ \\
\hline Financial result & 1,700 & 3,050 \\
\hline Result before tax & 39,800 & 61,560 \\
\hline Income tax & $(6,368)$ & $(9,850)$ \\
\hline Result of the exercise & 33,432 & 51,710 \\
\hline Gains from revaluation of PPE & 31,750 & 25,000 \\
\hline Total Comprehenisve Income & 65,182 & 76,710 \\
\hline
\end{tabular}

Source : own projection

The problem consists of two steps:

$>$ the change in accounting estimate, concerning the change in the annual amortisation pf the equipment, that will lead to an increase in expenses corresponding to 
the linear depreciation model; this change in the expenses with equipment depreciation has to be accounted prospectively in the financial statements;

$>$ the change in accounting policy, as we've underlined clearly that a change on the valuation base is defined as a change in accounting policy; thus, the transition from the historical cost convention, to the fair value measurement base has to be accounted retrospectively.

$\begin{array}{ll}2010 \quad & \text { PPE Purchasing value } \\ 2012 & \text { Annual depreciation expenses } \\ & \text { PPE Net reporting value } \\ & \text { Annual depreciation expenses } \\ & \text { PPE Net accounting value } \\ & \text { PPE Net reporting value (fair value) } \\ & \text { Positive difference } \\ & \text { Annual depreciation expenses (fair value) } \\ & \text { Annual transfer to the reported result }\end{array}$

\author{
$100.000 \mathrm{wn}$ \\ $2 \times 10.000 \pi m$. \\ $80.000 \mathrm{~nm}$ \\ $8 \times 18.898 \pi m$. \\ 40.000 น.m. \\ 60.500 น.m. \\ 20.500 น.m. \\ $4 \times 20.167$ นn \\ $4 \times 6.889 \pi m$.
}

In case of the changes in expenses from depreciation, the situation is simple, as the change is to be done prospectively. Thus, starting with the year when the change in the economic lifetime was decided, the expenses from PPE depreciation increase. In 2010 and

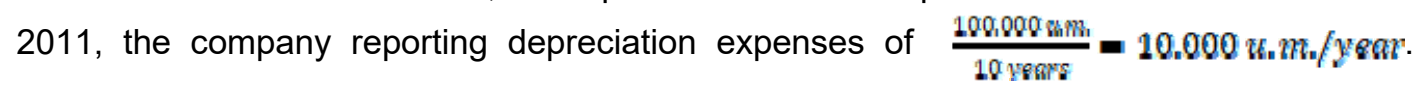
Once the economic lifecycle of the equipment is changed to 6 years, the estimation on the expenses with depreciation has to be adjusted, in order to incorporate this change of circumstance, but starting from the net historical accounting value of the equipment, namely $100.000 \kappa_{n} m_{n}-2 \times 10.000 \kappa_{n} m_{n}=80.000 \pi_{n} m_{\mathrm{s}}$

This way, the accounting estimate on the yearly expenses with depreciation for our

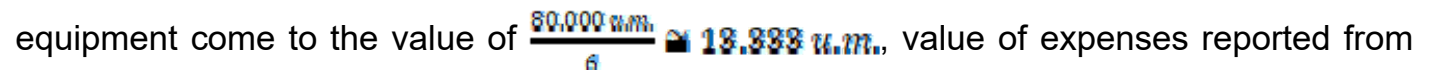
2012 until 2014 including.

Overall, the effects of those operations translate in the table below.

As we can see, the change in the accounting estimation of the depreciation expenses impact, not only the Income Statement, through a yearly increase of expenses of 3.8.8. $\pi_{n} m$, but also by a faster decrease of the net accounting value of the equipment. This can lead to some income tax savings, as a yearly cost saving would mean about $58 . \pi_{m} m$ On the other side, the assets return is negatively affected and the working capital level as well, meaning a decrease on the financial leverage of the company and deterioration of some of the covenants financial institutions use when approving financial credits for the company that want to start some new projects. 
Table 2

Financial impact of changes in accounting estimates versus changes in accounting policy, on the financial statements

\begin{tabular}{|c|c|c|c|c|c|c|c|c|}
\hline \multirow[b]{2}{*}{ Year } & \multicolumn{2}{|c|}{ Historical cost } & \multicolumn{2}{|c|}{$\begin{array}{c}\text { Fair value } \\
\text { (first scenario) }\end{array}$} & \multicolumn{2}{|c|}{$\begin{array}{c}\text { Fair value } \\
\text { (second scenario) }\end{array}$} & \multicolumn{2}{|c|}{ Differences } \\
\hline & $\begin{array}{c}\text { Deprecia } \\
\text { tion }\end{array}$ & $\begin{array}{c}\text { Reportin } \\
\text { g value }\end{array}$ & $\begin{array}{c}\text { Depreci } \\
\text { ation }\end{array}$ & $\begin{array}{c}\text { Reportin } \\
g \text { value }\end{array}$ & $\begin{array}{l}\text { Depreci } \\
\text { ation }\end{array}$ & $\begin{array}{c}\text { Reportin } \\
\text { g value }\end{array}$ & $\begin{array}{c}\text { Depreci } \\
\text { ation } \\
\text { (change in } \\
\text { accounting } \\
\text { estimate) }\end{array}$ & $\begin{array}{c}\text { Depreci } \\
\text { ation } \\
\text { (change in } \\
\text { accounting } \\
\text { policy) }\end{array}$ \\
\hline 2010 & 10,000 & 90,000 & 10,000 & 90,000 & 10,000 & 90,000 & - & - \\
\hline 2011 & 10,000 & 80,000 & 10,000 & 80,000 & 11,875 & 95,000 & - & 1,875 \\
\hline 2012 & 13,333 & 66,667 & 13,333 & 66,667 & 15,833 & 79,167 & 3,333 & 2,500 \\
\hline 2013 & 13,333 & 53,333 & 13,333 & 53,333 & 15,833 & 63,333 & 3,333 & 2,500 \\
\hline 2014 & 13,333 & 40,000 & 20,167 & 60,500 & 20,167 & 60,500 & - & - \\
\hline 2015 & 13,333 & 26,667 & 20,167 & 40,333 & 20,167 & 40,333 & - & - \\
\hline 2016 & 13,333 & 13,333 & 20,167 & 20,167 & 20,167 & 20,167 & - & - \\
\hline 2017 & 13,333 & 0 & 20,167 & 0 & 20,167 & 0 & - & - \\
\hline
\end{tabular}

Source: own calculation

On the other side, the change on the accounting policy has more visible impact, not only on the financial position and the financial performance of the company, but also an impact on the Comprehensive Income, through the potential gains obtained from the revaluation of the equipment. This is clearly creating an advantage to the company, as its financial covenants decrease and make more accessible the financial institution financing sources, at lower cost of capital.

This change in valuation method has to be presented to the users of the financial statements with the effects on the items on the financial statements, on a comparative way. For this we will make a distinction between the period before 2013 affected by the accounting policy change and the exercise 2013. The restatement of the financial statements means adjustments affecting the reported result with the carrying value calculated as necessary adjustment for the years, previous to 2013. Meanwhile, the adjustments to exercise 2013 will be done directly on the financial statements of the year of the change in the accounting policy.

Table 3

Comprehensive Income Statement (restatement)

\begin{tabular}{|l|r|r|}
\hline The Comprehensive Income Statement & \multicolumn{1}{|c|}{$\mathbf{2 0 1 4}$} & \multicolumn{1}{|c|}{$\begin{array}{c}\mathbf{2 0 1 3} \\
\text { adjusted }\end{array}$} \\
\hline Revenue from sale & 120,000 & 143,500 \\
\hline Cost of goods sold & $(70,000)$ & $(68,175)$ \\
\hline Gross margin & 50,000 & 75,325 \\
\hline Distribution expenses & $(6,500)$ & $(7,950)$ \\
\hline Administrative expenses & $(5,400)$ & $(12,540)$ \\
\hline Operating result & 38,100 & 54,835 \\
\hline
\end{tabular}


Studies in Business and Economics no. 14(1)/2019

\begin{tabular}{|l|r|r|} 
Financial revenues & 3,500 & 4,200 \\
\hline Financial expenses & $(1,800)$ & $(1,150)$ \\
\hline Financial result & 1,700 & 3,050 \\
\hline Result before tax & 39,800 & 57,885 \\
\hline Income tax & $(6,368)$ & $(9,262)$ \\
\hline Result of the exercise & 33,432 & 51,710 \\
\hline Gains from revaluation of PPE & 31,750 & 45,500 \\
\hline Total Comprehenisve Income & 65,182 & 76,710 \\
\hline Source: own calculation & &
\end{tabular}

For the period 2010-2012, the expenses with depreciation, in case of linear depreciation method, together with the change in the lifecycle of the equipment, sums up 8.8.8. $\mathrm{wm}$. As the company has information about the fair value of the equipment only from 2011 and 2012, according to the impracticability principle, we can see that the sum of the expenses with depreciation is $87.708 \mathrm{~m} m$. The difference is of $4.875 \mathrm{~km} m$, meaning an income tax saving of $700 \mathrm{n} m$

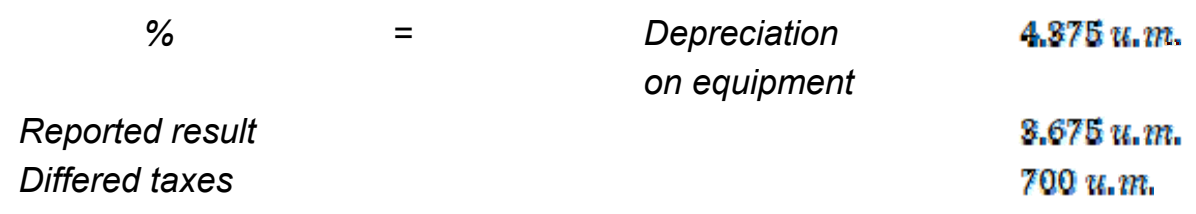

For exercise 2013, the expenses with depreciation would have been also bigger with $2.500 \mathrm{kn} m_{\mathrm{s}}$, in case the fair value base was considered for equipment accounting valuation, meaning also an income tax saving of $700 \% m$. This would lead the cost of goods sold to the value of $64.500 \pi_{n} m+8.675 \pi_{n} m=68.175 n_{n} m$ and the income tax, corresponding to the new result before taxes to the value of $9.262 \pi m$ for exercise 2013 . The value of $4.875 \pi_{n} m_{n} x 0.16=700 \pi_{n} m_{n}$ is considered and differed tax to collect from the state in time.

Overall, in case 2013 financial performance, we can observe an increase of $5.7 \%$ on the cost of goods sold, but a decrease of the income tax with about $5.97 \%$, resulting into a useful accounting policy change from the financial perspective. Also, we can see the positive effect of the use of fair value measurement in case companies have negative results from the previous period.

Table 4

Variation on the Statement of Changes in Shareholders' Equity

\begin{tabular}{|l|r|r|}
\hline & $\mathbf{2 0 1 4}$ & \multicolumn{1}{|c|}{$\mathbf{2 0 1 3}$} \\
\hline Initial balance of reported result, before restatement & 1,500 & $(8,500)$ \\
\hline Accounting policy change impact & $(5,775)$ & $(3,675)$ \\
\hline Initial balance of reported result, after restatement & $(4,275)$ & $(12,175)$ \\
\hline Result before tax & 33,432 & 51,710 \\
\hline Final balance of reported result & 29,157 & 39,535 \\
\hline
\end{tabular}

Source: own calculation

-30 - 
But we want to underline that, even there is temptation among preparers to proceed to accounting policy change, or much more frequent to changes in accounting estimate, this is forbidden, as those options are bounded, as stated on IAS 8, par. 14, by either a mandatory accounting policy change asked by change in accounting regulation, or in case the new policy lead to relevant financial statements that represent exactly company's financial position and financial performance. This uncertainty of the users of the financial statements can be reduced drastically in case of a wider financial transparency of the managers, through information disclosed by the notes to the financial statements that explain as detailed as possible:

$>$ the nature of the changes in accounting policy;

$>$ the premises on which the changes in accounting estimates have been made;

$>$ information about the impracticability effect on the comparative situation presented to illustrate the change in the accounting policy or in the accounting estimates;

$>$ reasons why the preparers consider the changes done provide much relevant and more exact financial information concerning the financial position and the financial performance.

Also, not as is usually done nowadays, the comparative situation presenting the effect of an accounting policy change has to be disclosed on an as lower as possible degree of aggregation of the information.

This example shows how important the difference between a change in accounting estimates and a change in accounting policy, as in case of retrospective changes the impact on the financial position. This impact is even higher on the comprehensive income is significant, especially when they are in discussion long prior periods, as the standard does not make any observation on how much the preparers can go back with the adjustments. The question remain what is preparers explanation when deciding on the level of transparency concerning those changes in accounting policy, or accounting estimates, as around the materiality concept there is still vivid debate to it should be applied in practice. This concept, together with the impracticability gate, as stated on IAS 8 , par. 25 , can lead in some situations to misleading financial statements. This vagueness has to be solved as, according to IAS 8, a change in accounting policy, if cannot be applied retrospectively, will have to be considered only a change in accounting estimates (ED, par. $32 \mathrm{~A}$ ), with the effects on financial position and financial performance as shown in the example above. This way, preparers' explanations could be essential on understanding the circumstances the financial statements were prepared.

\section{Conclusions}

The discussion around changes of estimates in accounting represent a never end discussion. The question is which would be the trigger that raise the need of a change in an accounting estimate, or an accounting policy. The solution can come from an emerging path of international accounting normalization, drawn up by a close cooperation between accounting profession, auditing profession and valuation profession. 
The auditors try to limit the inaccuracy of the financial information through different ways, reminding here their continuous and persistent position on how to introduce different analytical threshold, like the audit standard ISA 320 Materiality in the Identification and Evaluation of Misstatements does. This level of inaccuracy come from various sources, like Myddleton (2009) underlined, such as: the application of the going concern principle on financial reporting, the controversial issues circling around the use of the basis of measurement, the unreliable nature of money as a unit of account, the distinct perception between accounting and economic concepts defining the financial performance, or the factors describing the fraud triangle.

The professionals making valuation on entities, observe the importance of the financial transparency, in terms of a high volume of information disclosed by different corporate financial reports, like IVS 103 Reporting, which make reference to the need of information about how preparers have reached to the fair value of an assets, which was the rationale, the methods, the significant assumptions used in the measurement and whether the measurement was determined by reference to observable prices or recent market transactions.

All those can influence significantly the users of the financial information, helping them to reduce information asymmetry. This is even more needed, as changes in accounting estimates or accounting policies can lead to various forms of earnings manipulation and consequent premature negative capital markets reaction, based on markets theories like the adaptive capital markets hypothesis (Lo, 2017). Financial transparency is essential as, in case of actual capital markets theories, the perceptions configured on the investors' view are, at least as much important as the financial information, on market prices determination. This is because it is the only way managers can justify no earnings manipulation techniques (real activity manipulation - structural operations engineering, accruals manipulation - including changes in accounting estimates, or changes in accounting policies) considered on financial results reporting. Otherwise, the investors start to behave, rather based on psychologic instincts than economic rationale.

In the end, we believe IASB should include, together with IAS 1, IAS 7 and the revised Conceptual Framework, into a Post-implementation review project, as those standards are placed at the core of the financial reporting framework in compliance with IFRSs.

In parallel, especially in case of countries with a culture promoting financial reporting opacity, the national standard-setting bodies have to involve on asking for a higher degree of financial transparency and have to sanction drastically any attempt to proceed to malicious earnings manipulation.

Nonetheless, financial statements users have to become more careful on how to interpret the financial figures, as the accounting estimates imply a certain degree of subjectivism. They have to understand that the potential litigation costs do not constitute a warranty the managers of an entity will not proceed to different changes in accounting estimates, or in accounting policies. They have to learn, even following analysts' earnings forecasting, how to deep dive into the financial statements items and avoid to be trapped in the functional fixation practice. 


\section{References}

Albrecht A., Kim K., Lee K.J. (2017), Changes in Accounting Estimates: Are the current disclosure requirements sufficient to deter managerial opportunism?, working paper, available on www.ssrn.com;

CECCAR (2013), International Financial Reporting Standards, CECCAR Publishing House, Bucharest;

Christensen H.B., Nikolaev V.V. (2012) Capital Versus Performance Covenants in Debt Contracts, Journal of Accounting Research, vol. 50, issue 1, pp. 75-116;

Dennis I. (2014), The Nature of Accounting Regulation, Routledge Publishing House, New York;

Fields T.D., Lys T.Z., Vincent L. (2001), Empirical research on accounting choice, Journal of Accounting and Economics, vol. 31, pp. 255-307;

Gebhardt G., Mora A., Wagenhofer A. (2014), Revisiting the Fundamental Concepts of IFRS, Abacus vol. 50 , issue 1 , pp. 107-116;

Hail L. (2013), Financial Reporting and Firm Valuation: Relevance Lost or Relevance Regained?, Accounting and Business Research, vol. 43, issue 4, pp. 329-358;

Jianu I. (2012), Valuation in accounting. Theory and method, Economic Publishing House, Bucharest;

Kothari SP., Ramanna K., Skinner D.J. (2010), Implications for GAAP from an Analysis of Positive Research in Accounting, Journal of Accounting and Economics, vol. 50, issues 2-3, pp. 246286;

Leuz C., Wysocki PD. (2016), The Economics of Disclosure and Financial Reporting Regulation: Evidence and Suggestions for Future Research, Journal of Accounting Research, vol. 54, issue 2, pp. 525-622;

Lev B., Li S., Sougiannis T. (2010), The Usefulness of Accounting Estimates for Predicting Cash Flows and Earnings, Review of Accounting Studies, vol. 15, issue 4, pp. 779-807;

Lo A.I. (2017), Adaptive Markets Financial Evolution at the Speed of Thought, Princeton University Press, NEW Jersey, Canada;

Menzefricke U., Smieliauskas W. (2016), Are all accounting estimates auditable? Some evidence on estimated returns in pension accounting, working paper, available on www.ssrn.com;

Myddleton D.R. (2009), Margins of Error in Accounting, Palgrave, New York;

Nobes C.W., Stadler C. (2015), The qualitative characteristics of financial information and managers' accounting decisions: evidence from IFRS policy changes, Accounting and Business Research, vol. 45, issue 5, pp. 572-601;

www.ifrs.org;

www.iasplus.com 